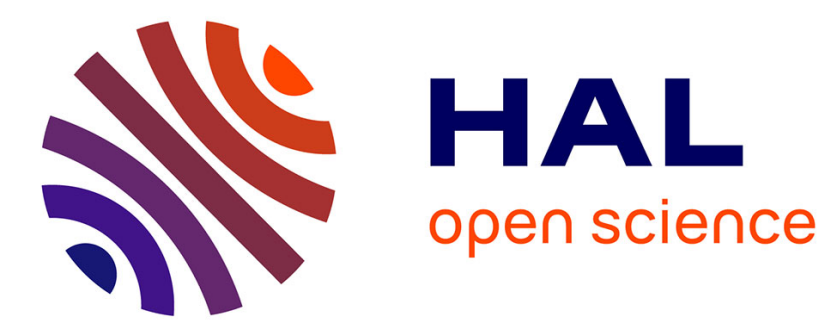

\title{
Power Transmission Network Investment as an Anticipation Problem
}

Vincent Rious, Yannick Perez, Jean-Michel Glachant

\section{To cite this version:}

Vincent Rious, Yannick Perez, Jean-Michel Glachant. Power Transmission Network Investment as an Anticipation Problem. Review of Network Economics, 2011, 10, 10.2202/1446-9022.1284 . hal01424616

\section{HAL Id: hal-01424616 https://hal.science/hal-01424616}

Submitted on 2 Jan 2017

HAL is a multi-disciplinary open access archive for the deposit and dissemination of scientific research documents, whether they are published or not. The documents may come from teaching and research institutions in France or abroad, or from public or private research centers.
L'archive ouverte pluridisciplinaire HAL, est destinée au dépôt et à la diffusion de documents scientifiques de niveau recherche, publiés ou non, émanant des établissements d'enseignement et de recherche français ou étrangers, des laboratoires publics ou privés. 


\section{Review of Network Economics}

Manuscript 1284

\section{Power Transmission Network Investment as an Anticipation Problem}

Vincent Rious, Microeconomix and RSCAS-EUI

Yannick Perez, University Paris-Sud 11, Supelec and

RSCAS-EUI

Jean-Michel Glachant, Florence School of Regulation and RSCAS-EUI 


\title{
Power Transmission Network Investment as an Anticipation Problem
}

\author{
Vincent Rious, Yannick Perez, and Jean-Michel Glachant
}

\begin{abstract}
Power generation and transmission are complementary activities that must be coordinated to ensure an optimal use and development of the transmission network. This coordination is today more difficult in a liberalized system, because of unbundling and the freedom for investors to choose their generation technologies (Joskow, 2006). Shorter investment time between generation and network create uncertainty for the network planning and congestions. In the economic literature, the efficiency of anticipating generation investment has been under-evaluated assuming that it is a cost free activity. Our model evaluates the effect of anticipation costs and defines in which cases the previous results by Sauma and Oren $(2006,2007)$ could still hold.
\end{abstract}

KEYWORDS: liberalized power system, transmission network, planning, investment, anticipation

Author Notes: The authors gratefully acknowledge helpful comments on earlier drafts of this paper from Prof. Dominique Finon, Mauricio Cepeda, members of the Network Research Group of the Faculty Jean Monnet (GRJM), and from two anonymous referees and participants of the 1st International scientific conference "Building Networks for a Brighter Future" organized by NGInfra and sponsored by IEEE Systems, Man \& Cybernetics Society, in Rotterdam, 10-12 November 2008. Authors want also to acknowledge the comments received on latest versions of this paper at ISNIE Stanford Conference 2011, the INFER Workshop 2010 and the AFSE conference 2010, and from two other anonymous referees. Vincent Rious gratefully acknowledges the financial and scientific support he received from the French Transmission System Operator (Réseau de Transport d'Electricité) for this work while he was a $\mathrm{Ph}$. D student under the supervision of Prof. Jean-Michel Glachant at both the GRJM Team at the Research Center ADIS University Paris XI, and at the Energy department at Supélec. The remaining errors are solely those of the authors'. 
Rious et al.: Power Transmission Network Investment

\section{Introduction}

Power generation and transmission are complementary activities that must be coordinated to ensure an optimal use and development of the transmission network. The coordination between generation and transmission is more difficult in a liberalised power system, not only because these activities are unbundled but also because of the investors' freedom to choose their generation technologies (Joskow, 2006). The power reform has prompted the generation investors to build mainly power plants with short building time, such as Combined Cycle Gas Turbines (Glachant, 2006) or wind farms (ETSO, 2007). At the same time, the right of way of powerlines faces raising strong and diverse oppositions (ETSO, 2006). These conflicting trends increase the time needed to build transmission lines and leads sometimes to the point that the powerlines cannot be built.

The differences in investment time between generation and network create uncertainty for the network planning. Indeed, these differences in investment times are all the more detrimental that the generation capacities of these new plants are significant compared to the transmission lines capacities. The connection of these power plants can thus create congestion while the network is not upgraded yet.

Rious et al. (2009a \& b) showed that the price signal alone cannot solve the problem of coordination between investments in power generation and transmission. First the locational signals are institutionally hard to implement because the TSOs that own the power transmission assets are poorly interested in it. Then the locational signals have a limited efficiency because of the intrinsic lumpy cost structure of network investment. Lastly generation has so many other locational constraints (access to water, primary energy, land, acceptability from local population, etc.) that the locational signals from power transmission network are then weakly operative.

Our claim is that a logical solution to this problem of differences in investment time between generation and network could be that the Transmission and System Operator (TSO) anticipates the connection of these new generation plants and the congestions that they may create. By anticipating the connection of generation plants, the TSO can adapt the network planning so that the network upgrade is operational when the generator is just built. To implement this process, the TSO must anticipate the administrative procedures required before the network upgrading. But if the network is not eventually upgraded, this anticipation is costly because of the administrative procedures and their cost. Logically, the cost-benefit analysis for the efficiency of anticipating the generation connection and of the required transmission investment thus depends on the anticipation cost and on the uncertainty on the effective generation connection and the required transmission investment. 
This paper evaluates the efficiency of the strategy of anticipating the connection of power plants for the TSO in terms of the minimization of the network cost. The question is then to know if it is efficient for such a TSO to forecast the development of its network in advance of the request of connection so that there is sufficient planned transmission capacity to accommodate these new generation investments.

The efficiency of anticipating generation investment has been little evaluated in the literature, either from an empirical or from a theoretical point of view. The literature about power transmission has focused mainly on regulation (Joskow, 2008) and use pricing (Hogan, 1992). Inversely, the problem of investment coordination has received little attention while it remains a central problem to ensure long term efficiency of the liberalised power systems (Brennan, 2009). The paper of ETSO (2006) highlights the problem of coordination between transmission and generation investments on the European power system caused by the time needed to have the administrative authorization to build transmission upgrade. But ETSO proposes no solution to this problem, except claiming for reducing this duration. Brattle Group (2007), in a report done for the Dutch TSO, recommends that Tennet should anticipate transmission investment so that the connection of generator is shortened and there is less congestion on the network. The conclusion of Brattle Group is grounded on the experience of the California System Operator CAISO which plans to anticipate the transmission line to windy areas to ease and accelerate the development of renewable projects (FERC, 2007). Even if Brattle Group and CAISO have noticed that anticipation can be costly, they have not clearly established if the proactive behaviour of the TSO is more efficient than the reactive one. In the economic literature, Sauma \& Oren (2006, 2007) are the only ones to propose a model where they evaluate the efficiency of anticipating generation investment for more efficient network upgrades in the liberalised power system considering also potential use of market power. But they implicitly assume that anticipation is free. But as shown by Christiner (2007) anticipation is costly in reality and this cost can be quite high, up to $40 \%$ of the cost of investment project in the case of the Austrian 380kV-ring. So the cost of anticipation may then challenge and overcome the benefits of anticipating new connections of generators and the associated network development. Taking into account in a quantitative manner the effect of anticipation costs will then allow us to consider in which cases the results by Sauma and Oren $(2006,2007)$ could still hold. We then evaluate if anticipation remains an efficient strategy from a social point of view even when taking into account the cost of anticipation.

Our model has four characteristics, which makes it noticeable compared to previous studies about the efficiency of TSO of anticipating generation investment. 
$1^{\circ}$ The connection of a generator to the grid is a probabilistic event. Even in areas where there are primary energy sources, the connection of a generator remains uncertain because of the market uncertainty and because of the administrative agreements that the generator may not receive.

$2^{\circ}$ There is a difference between the time to build a power plant and the time to build the needed powerline to evacuate power. This difference can be quite high because of the lengthy administrative procedures for the right of way of powerline and because of the increasing local opposition for powerline. And this difference in the generation and transmission investment dynamics can create congestion while the generator is connected but the network is not upgraded.

$3^{\circ}$ Facing the uncertain connection of generators, the TSO can choose two strategies, the proactive one and the reactive one to anticipate the connections or not. If the TSO is reactive, he develops the network only once the generator is sure to invest in a precise location. But there is then generally a delay between the moment when the power plant can be operational and the moment when the network upgrade is operational. This creates congestion and is costly. Otherwise, the TSO can be proactive and anticipates the connection of generator. The network upgrade is then operational when the power plant is just operational.

But if the TSO is proactive, anticipation is costly. This is because, if the power plant is eventually not built and then not connected to the network, the TSO has engaged some costs through the administrative procedures required to build powerline for nothing.

This paper is organised as follow. Section 2 shows that the need to coordinate generation and transmission varies with the considered generation technology. A model is developed in section 3 to evaluate and find the conditions of efficiency of anticipating the generation connection and the required transmission investment. Section 4 concludes and raises some implications of our work for academia, TSO managers and regulators.

\section{Generation technology and the coordination of generation and transmission investments}

In a liberalized power system where generation and transmission are generally unbundled, the need to coordinate these activities varies with the generation technology. Indeed, the time needed to build powerlines can be longer than the time needed to build some generation technologies. Our review on this problem show that it takes at least five years to build a powerline and on average seven to ten years in Europe (ETSO, 2006).

There are two steps to build a powerline. First the TSO must fulfil the administrative procedures to have the right to build the line. This step to obtain the administrative agreements lasts at least three years. But in practice, it can last 
five years on average. The second step consists in building the line. This step is quite short, about two years only, and faces few uncertainties. Getting administrative agreements is then the crucial step for the time between the investment decision and the completion of the project. The uncertainty on building the powerline comes from this period because of the local oppositions to the right of way of the transmission lines, which can result in postponing the line project or even in the impossibility to realise it.

The choice of generation technology also impacts the need of anticipation of network investment. Besides, some generation technologies have an important notional size while they can be more quickly built than the network requirement. The connection of these power plants can then create network congestion while the TSO has not yet upgraded his network to evacuate this new power. This can make the accommodation of these generators more difficult. This impact on the different generation technologies on the network is captured in table 1 by the third column that gives the notional size of an installation divided by the time to build it.

Table 1. Building time of different generation technologies (RAE, 2004; DGEMP, 2003)

\begin{tabular}{|l|c|c|c|}
\hline \multicolumn{1}{|c|}{ Generation technology } & $\begin{array}{c}\text { Time } \\
\text { needed to } \\
\text { build (year) }\end{array}$ & $\begin{array}{c}\text { Notional size } \\
\text { (MW) }\end{array}$ & $\begin{array}{c}\text { Notional size divided by } \\
\text { time to build (MW/an) }\end{array}$ \\
\hline Combustion turbine & 1 & 40 & 40 \\
\hline Coal & $4-5$ & 150 to $1600^{*}$ & 30 to $400^{*}$ \\
\hline $\begin{array}{l}\text { Combined Cycle Gas Turbine } \\
\text { (CCGT) }\end{array}$ & 2 & 800 & 400 \\
\hline Nuclear & $5-7$ & 1600 & 200 to 300 \\
\hline Wind onshore & 2 & 25 & 12.5 \\
\hline offshore & 2 & 100 & 50 \\
\hline
\end{tabular}

*Depending on technologies

Here it is worth the cost to note that some generation technologies are easier to handle for TSO. For instance, coal and nuclear generation units face similar time horizon for construction than network investments. The TSO can then deal with their connection when required at the beginning of the project.

To the contrary, the Combined Cycle Gas Turbine (CCGT) and the wind farms can be built and connected faster than the network can be modified to accommodate them. The time to build CCGT is quite short since it is only about two to three years (RAE, 2004; DGEMP, 2003). The CCGT investors can then respond quickly to the power market needs. The notional size of CCGT is 800 MW. It cannot be neglected compared to the transmission capacity of powerlines between 1000 and $2500 \mathrm{MW}$ for the voltage level where they connect (400 kV or 
$225 \mathrm{kV}$ ). Therefore, these new generation units can create important congestion before the TSO can upgrade the network. A similar conclusion applies to the network where wind farm connect with capacity of powerlines around $100 \mathrm{MW}$.

This phenomenon becomes very important in liberalized markets worldwide because these two last technologies are actually the preferred ones in Europe and in the USA. For the CCGT, four elements account for this preference. First of all, the investment cost of CCGT is small compared to those of other base or shoulder generation technologies, such as coal or nuclear. Besides, in the 90's, the CCGT had the smallest marginal cost because gas was cheap (Glachant, 2006). Third the CCGT investments are less risky than other base investments. Indeed, the CCGT investments induce and increase the correlation between the electricity prices and the gas prices. This is because the price of electricity is more and more set by a marginal gas unit as the capacity of the CCGT technology expands. Therefore, the revenue of CCGT investors is all the more constant and all the less risky as this technology stands for an increasing share of the energy mix (Roques et al., 2008). Consequently, the more the CCGT represents an important share of the energy mix, the more the investors are incentivised in investing in this technology, even if the increase of the gas price ends in making this technology less competitive compared to coal for instance. The last reason that explains the development of CCGT is its low level of CO2 emissions. Indeed, in a growing number of countries, the $\mathrm{CO} 2$ emissions must be paid either through a market price or a tax. The $\mathrm{CO} 2$ emission level of the generation technologies has then more and more impacts on their relative marginal cost. We see three types of influence of $\mathrm{CO} 2$ emissions on the development of CCGT. $1^{\circ} \mathrm{CO} 2$ emission limits the development of CCGT as a base load technology because other technologies like nuclear or renewable are able to produce base energy without emitting $\mathrm{CO} 2.2^{\circ}$ However, when you consider a CCGT like a shoulder load power plant, the payment of $\mathrm{CO} 2$ emissions favours this technology because it emits less $\mathrm{CO} 2$ than a coal power plant. This effect depends on the relative values of gas price, coal price and $\mathrm{CO} 2$ price. $3^{\circ}$ This second characteristic combined with its flexibility makes CCGT the adequate technology to balance the intermittent production of renewable energy sources like wind or solar power. From this point of view they are at the same time substitute and complement.

The power reform has not only introduced competition in generation but also favoured the development of Renewable Energies because they generate electricity with less or without detrimental environmental effects. Various economic instruments support the development of wind technology because they are not competitive with conventional power sources otherwise ${ }^{1}$. In a lot of

\footnotetext{
1 There exist three main subsidy mechanisms to promote the Renewable Energies: call for public tenders, price mechanisms (feed-in tariff), and quantity mechanisms with tradable property rights (green certificates) (Finon \& Perez, 2007).
} 
countries, these mechanisms induce a quick and important development of wind electricity because they ensure a guaranteed profitability for a long period to the investors that choose this technology $y^{2}$. For instance, these last ten years, three gigawatts and a half of wind power have been installed in Denmark, nineteen in Spain and twenty five in Germany ${ }^{3}$. And other important developments of wind power capacity are planned in some countries as in Great Britain or in France. Such massive connection of wind power to the transmission network is problematic for two reasons. Firstly, compared to the time to upgrade the network, the time to build wind farms is quite short, since it is about two to three years. Secondly, the network must adapt to the massive connection of such atypical power plants. This generation technology is atypical because its power delivery is intermittent and because they locate on network with small voltage level whereas these voltage levels were originally designed to supply load, not to accommodate decentralised generation. Besides, although the wind power is distributed generation, the wind farms are concentrated in geographical areas with wind (see figure 1).

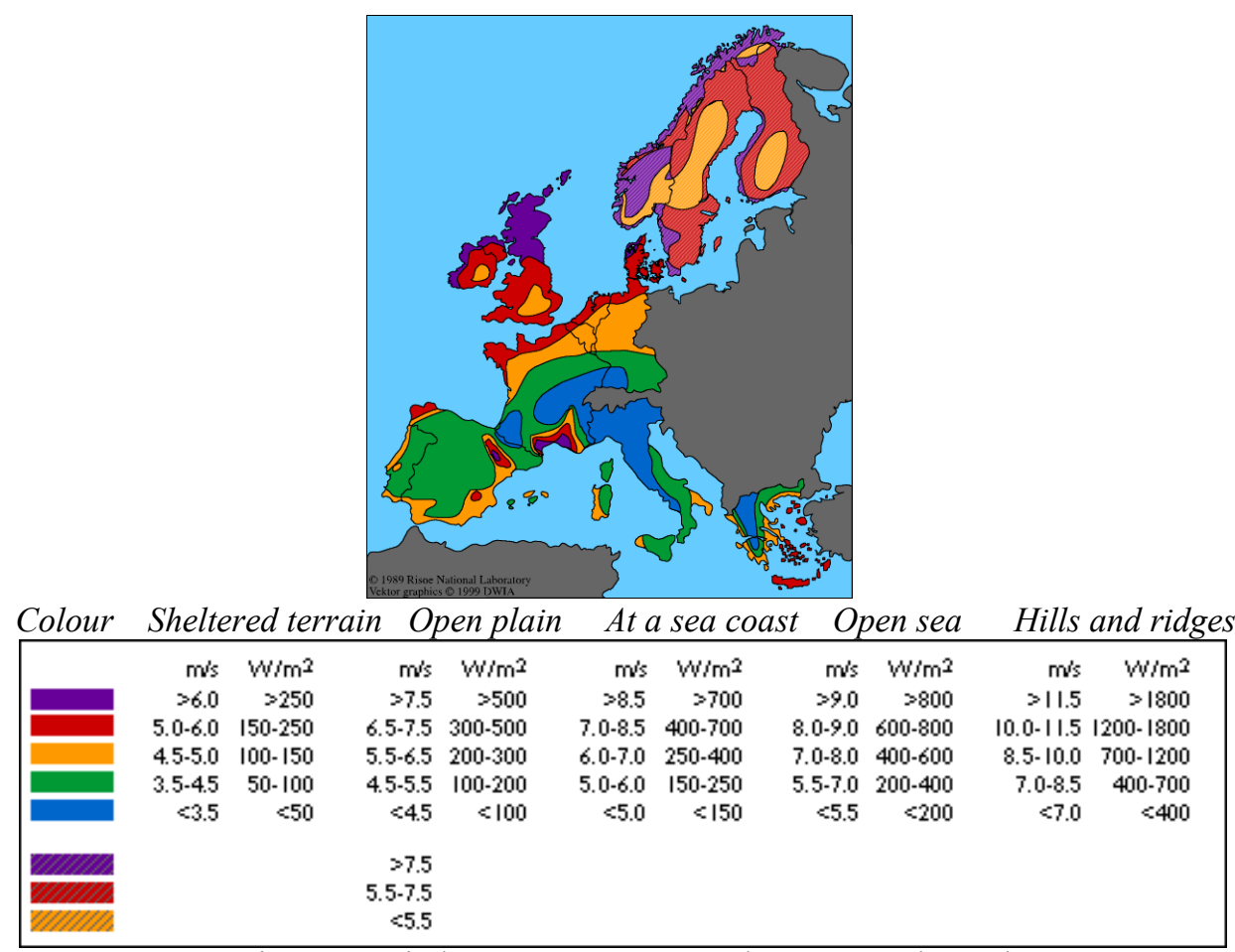

Figure 1. Wind Resources at $45 \mathrm{~m}$ Above Ground Level

(Source: http://www.windpower.org/en/tour/wres/euromap.htm)

\footnotetext{
${ }^{2}$ Despite the wind power investments are capital-intensive, about $1500 € / \mathrm{kW}$, that is to say similar to the investment cost of big coal power plants (RAE, 2004).

${ }^{3}$ Source : www.ewea.org
} 
Their massive connection can then require upgrading the transmission network to evacuate the power generated by all the wind farms in one area towards load centres. Therefore, the problem is the following one: CCGT and wind farm can require important network upgrading whose time to build is quite longer than the time to build these power plants. There may then be congestion between the moment when these generators connect to the network and the moment when the TSO upgrades the facilities.

The TSO can anticipate the connection of these plants and consequently plan the network investment to avoid these congestions. Then it can better deal with the uncertainty coming from the difference in time to build power plants and time to upgrade the network. But this work of anticipation is costly. As a consequence it is necessary to evaluate the efficiency of anticipating the network investment to accommodate new generators.

\section{A model to evaluate the efficiency of anticipating network investments}

There is a noticeable difference in time to build CCGT and wind farm and in time to upgrade the network to accommodate these power stations. In order not to limit and even to facilitate the development of these generation technologies, it can be efficient to anticipate their connections. The network can then have sufficient capacity to accommodate them. The TSO can anticipate the connection of these generators and can so study in advance the opportunity of upgrading the network.

For the CCGT, this anticipation can be done at the same time as the gas network upgrading. The development of new entry points or new Liquefied Natural Gas (LNG) entry points can attract CCGT investors and modify the location of these generators on the electricity network. For windfarm, this anticipation can be done in the framework of a regional development planning to identify areas to locate these generators ${ }^{4}$. More generally, this approach can be done identifying an available primary energy source that requires the upgrading of the transmission electricity network to be exploited ${ }^{5}$. For instance, this is the approach adopted for the National Transmission Congestion Study of the United States Department of Energy (USDoE, 2006) and for the development plan of the Norwegian transmission network (Statnett, 2005), for the study to increase the capacity of the interconnectors in the Nordel electricity network (Nordel, 2004) .

Not only anticipating the connection of these power plants compensates for the time lag between generation and transmission investments, but also it leads

\footnotetext{
${ }^{4}$ It is the case of the Wind Development Areas (Zones de Développement Éolien) in France (in French, loi de programme du 13 juillet 2005 fixant les orientations de la politique énergétique).

${ }^{5}$ In the case of gas, energy can be transmitted without converting it. Therefore, the process of TSO for anticipating is part of a general approach to minimise the cost while arbitrating between the cost of transmitting gas and the cost of transmitting electricity.
} 
to other benefits. If the TSO made this process public, it gives better information to the market participants. In particular it can signal new opportunities to locate and to access primary energy sources. It can also reveal some problems linked to security of supply. Some generation technologies are very concentrated, whereas the transmission network cannot evacuate all their cumulated production toward the load centres when it is necessary.

Such anticipation does not commit the TSO to invest if it eventually reveals to be unnecessary. Because, once the TSO has obtained the administrative agreements required before building the power line, the TSO can decide to upgrade the network effectively only after the relevant assumptions of the investment project become true or extremely certain. To the contrary, a TSO whose objective is to maximise the social welfare can decide to cancel a planned investment if the relevant conditions does not eventually happen. One then notices that, by anticipating the administrative phases preliminary to the construction of a line, the TSO has more options than if he is passive regarding the connection demands from new generators.

It is noticeable that the above rationale does not depend nor on the locational structure of the network access fee neither on the choice of (either nodal or zonal) energy market design. Indeed, the change in the locational structure of the network access fee and in the energy market design only modifies where the TSO may apply this rationale. This is because the change in the locational structure of the network tariff and of the energy price only modifies the area where the generator may find it profitable to locate, which, in return, modifies the location where congestion may appear.

The TSO can implement two strategies to anticipate transmission reinforcements. $1^{\circ}$ The TSO can be proactive and anticipates the change in the generation mix and location. $2^{\circ}$ The TSO can be reactive and upgrades the network only once he knows where and when the power plants connect. Sauma and Oren $(2006,2007)$ show that the proactive TSO is always more efficient ${ }^{6}$ than the reactive one in an uncertain environment. But they implicitly assume that anticipation has no cost while it is costly in reality and this cost can be quite high (Christiner, 2007).

The essential parameters to evaluate the efficiency of the anticipating the generation and transmission investment are then the three following ones: $1^{\circ}$ the cost of anticipating investments, $2^{\circ}$ the difference between the time to build power plants and the time to upgrade the network, and $3^{\circ}$ the probability of connection of the generators. Our model allows us to measure the influence of these different elements on the opportunity for the TSO to be proactive. Next, we

\footnotetext{
${ }^{6}$ From the point of view of the minimisation of the expected social cost.
} 
will illustrate our results on two representative cases of connection, respectively of a CCGT and a wind farm.

\section{A necessary condition for anticipation to be optimal}

We present here a model where the congestion cost is assumed given and sufficient to require a transmission investment ${ }^{7}$. In our modelling, we search for the conditions when it is efficient from the point of view of the minimization of the expected social $\operatorname{cost}^{8}$ to anticipate the connection of power plants whose building time is shorter that the time needed to upgrade the network.

We consider the two TSO behaviours -proactive and reactive- that we described just above.

- To anticipate the connection of new power plants, a proactive TSO realizes in advance the study of the transmission investment project and the administrative procedures that are required to have the agreements to build the powerline.

- A reactive TSO does not study the project nor does he make the administrative procedures in advance. He realizes these steps only once the generators have effectively asked to connect to the network.

We assume that in a step before the application of our modelling, an expert has highlighted the nodes or areas where generators are more likely to connect and the lines that may experience congestion. It is similar to the approach used in the National Electric Transmission Congestion Study of the U.S. Department of Energy (USDoE, 2006). This phase consists in determining where it will be needed to upgrade the network taking into account the primary energy sources and the areas where the generators will be able to locate. The goal of our modelling is then not to find where to upgrade the network. Our modelling finds the lines whose forecasted constraints are such that it is efficient to anticipate their upgrading and especially to anticipate the long administrative procedures. Anticipating can result in accommodating the considered generation technologies more efficiently and more quickly ${ }^{9}$.

\footnotetext{
${ }^{7}$ The problem of calculating the congestion cost is dealt with further details in this paper with the realistic case of connection of a CCGT and a wind farm (see paragraph IV).

${ }^{8} \mathrm{We}$ assume that the social cost includes the external cost of CO2 emissions as a benevolent TSO would do it (Realisegrid, 2010). We also assume that the TSO is not subject to conflict of interest, in particular when there might have substitutability between generation and transmission investment. This is coherent with our approach in terms of minimization of the expected social cost and the subsequent benevolent behavior of the TSO.

${ }^{9}$ Our model can also test the robustness of an already decided transmission investment against the connection of new CCGT or windfarms.
} 


\section{Definitions and assumptions}

For each year $y$, we define two types of congestion $\operatorname{cost}^{10}$ that we note $C U_{y}$ and $C W_{y}$ respectively with and without network reinforcement. Then, whatever the year $y$, the congestion cost without reinforcement is greater than the congestion cost with reinforcement, that is to say $C W_{y} \geq C U_{y}$. For a year $y$, the congestion cost $C W_{y}$ or $C U_{y}$ depends only on reinforcing the network, and not on the moment when the network is upgraded. We assume neither particular topology of the network nor contingency here, even if, of course, the TSO takes them into account while calculating congestion cost.

We define two functions of discounted and cumulative congestion cost over several years $d$ with a discount rate $a$.

- The first function, $C W(d)$ is the total congestion cost discounted during $d$ years before upgrading the network.

- The second function, $C U(d, T)$ is the total congestion cost discounted during $T$ years after the network being upgraded the year $d$. We will use the parameter $T$ so that the congestion cost as a whole (either with or without transmission investment) is evaluated over the same duration whatever the moment of network upgrading ${ }^{11}$.

$C W(d)$ and $C U(d, T)$ can be expressed as functions of $C W_{y}$ and $C U_{y}$ as follow:

$$
C W(d)=\sum_{y=1}^{d} \frac{C W_{y}}{(1+a)^{y}} \text { and } C U(d, T)=\sum_{y=d+1}^{d+T} \frac{C U_{y}}{(1+a)^{y}}
$$

\footnotetext{
${ }^{10}$ Congestion cost is calculated as the difference between the social welfare assuming there is no network constraint and the social welfare considering the network limits. Other said, congestion cost is the loss of social welfare arising from the network constraints. With inelastic demand and benevolent producer, congestion cost is then the generation overcost plus the Value of Lost Load induced by the network constraints. The integration of the Value of Lost Load in congestion cost permits to integrate any reliability criteria in the calculation of congestion cost (Stoft, 2006).

${ }^{11}$ If CU was evaluated over a fixed duration, for instance 10 years, whatever the moment when the network is upgraded, this would mean that congestion costs (without then with upgrade) would be assessed for 10 years if the investment was made at once, and for $10+d$ years if it is delayed. This would normally inflate the costs of a delayed investment, and bias the calculations towards recommending immediate investment.
} 
Figure 2 exemplifies the two sums $C W(d)$ and $C U(d, T)$ with $\mathrm{T}=10$ years on this example ${ }^{12}$. For illustrative reasons, we assume that the terms $C W_{y} /(1+a)^{y}$ and $C U_{y} /(1+a)^{y}$ increase linearly with time ${ }^{13} \cdot C W(d)$ corresponds to the grey trapezoid and $C U(d, T)$ corresponds to the black trapezoid.

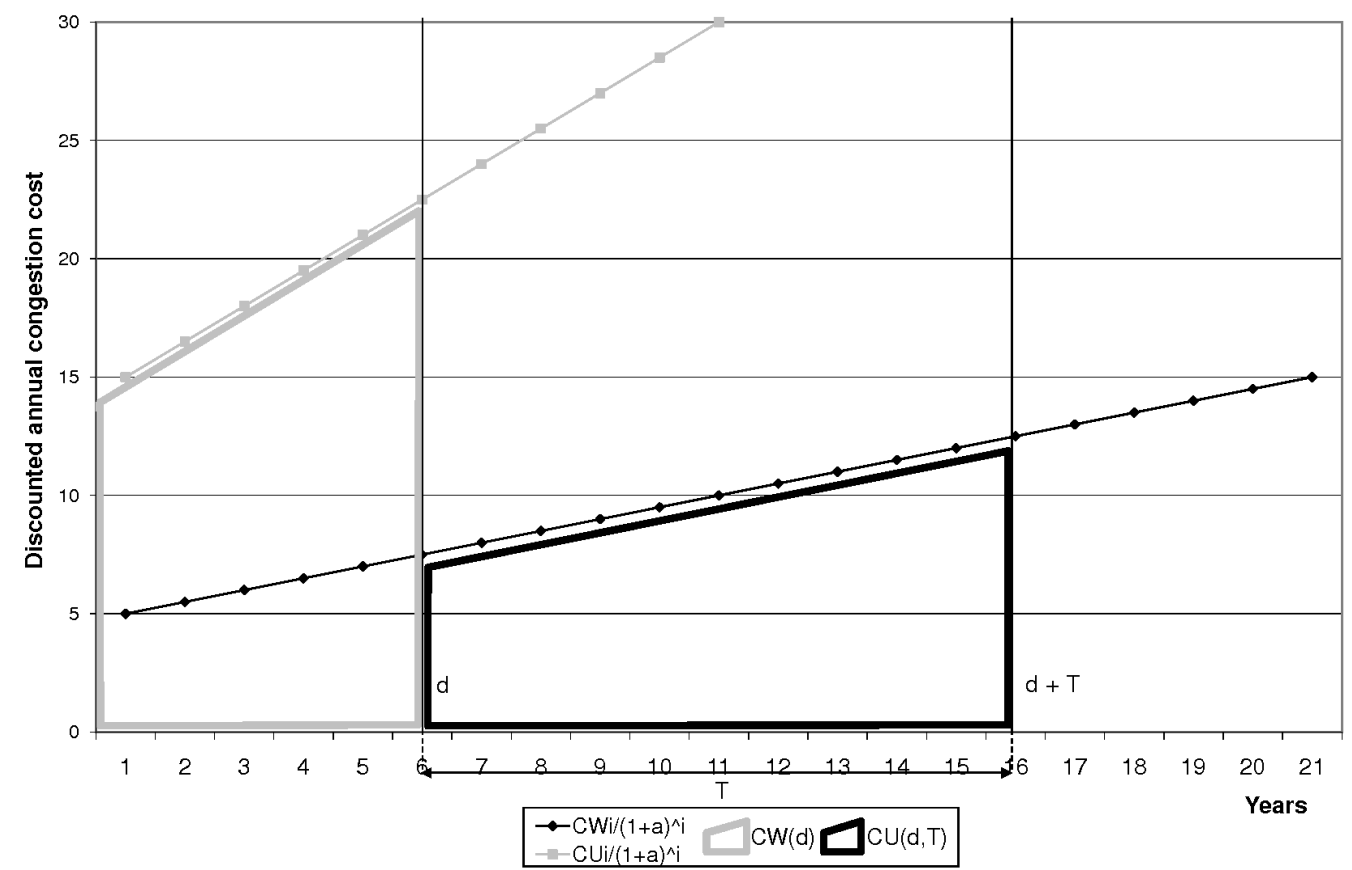

Figure 2. Definition of $C W(d)$ and $C U(d, T)$

We assume that the network must be reinforced as soon as a power plant connects. That is to say that the cost saved by the network upgrading as soon as the generator connects is greater than the related transmission investment cost. Figure 3 illustrates the cost saved by upgrading the network as a function of $C W(10)$ and $C U(0,10)$. The greyed area stands for this saved cost.

\footnotetext{
12 The avoided costs thanks to the reinforcement of the network are generally evaluated at most only over ten years sometimes over twenty years for two reasons. First it is difficult to know accurately the state of the power system beyond ten years. Second discounting considerably decreases the costs beyond this duration.

13 This may not be the case in reality.
} 


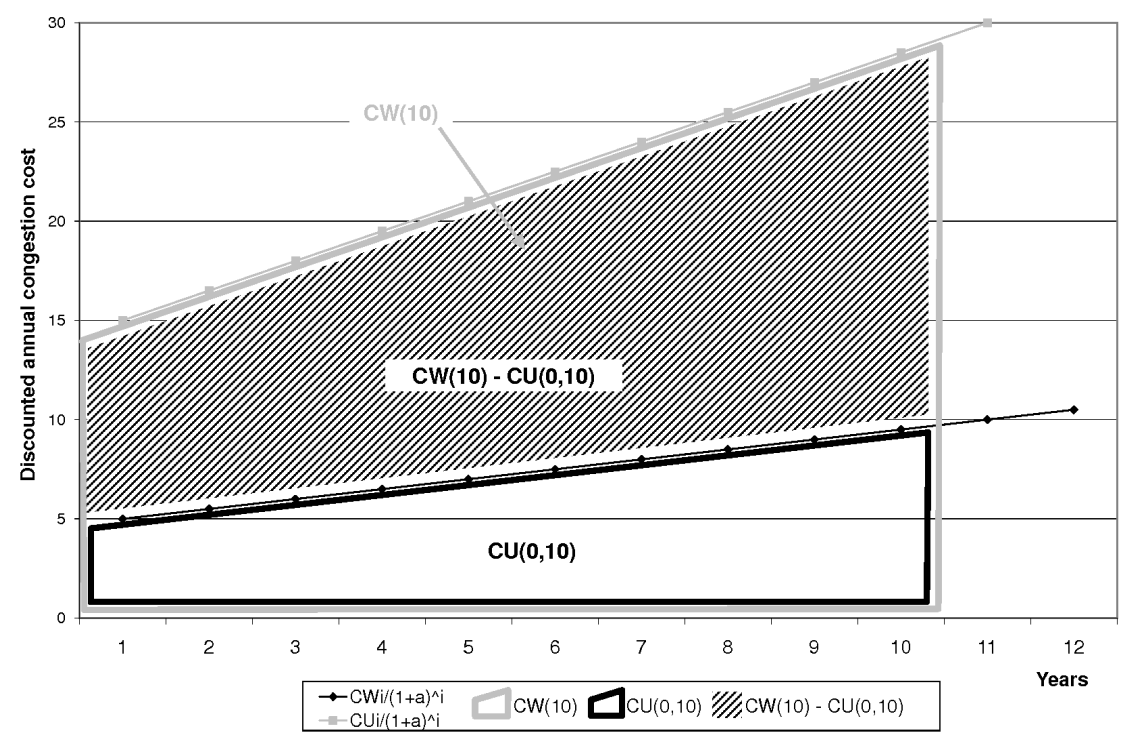

Figure 3. Cost saved by upgrading the network as a function of $C W(10)$ and $C U(0,10)$.

The equation (2) links $C W(10), C U(0,10)$ and the investment cost $I$.

$$
C W(10)-C U(0,10) \geq I
$$

With $C W(10)-C U(0,10)=\sum_{i=1}^{10} \frac{C W_{i}-C U_{i}}{(1+a)^{i}}$

The moment of reference for discounting the cost over time is chosen so that the most conservative condition about the efficiency of a proactive TSO is obtained. This instant is then the moment when the generation investment begins to produce power. This convention degrades the advantage of discounting for the strategy of anticipating compared to the strategy of not anticipating. Indeed, if the beginning of the administrative procedures has been chosen as the instant of reference for discounting, the discounting of cost would have mechanically decreased the cost of network investment. By taking the beginning of production of the power plant as a time reference for discounting, this effect is avoided.

\section{Expected social cost for a reactive TSO}

A reactive TSO does not anticipate the connection of generators. It studies the network upgrading only once the power plant has been planned and approved. The network investment to evacuate this power is ready to serve only $d$ years after the connection of the generation unit, where $d$ is the difference between the time 
to build a power plant and the time to upgrade the network. Figure 4 exemplifies this sequence of the generation and transmission investments. The timeframe of generation is in grey while the timeframe of transmission is in black. While the power plant has already connected and the network has not yet been upgraded, there is congestion for $d$ years.

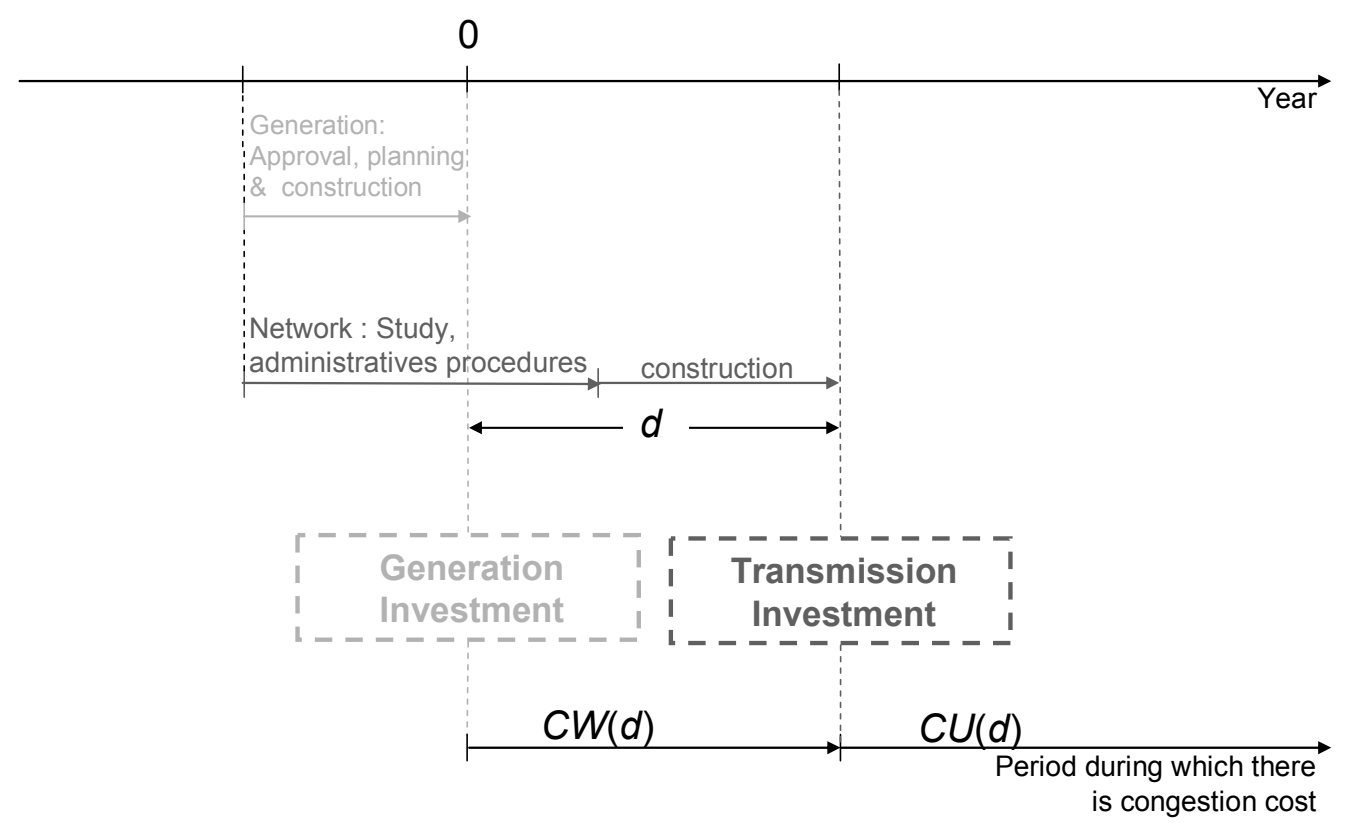

Figure 4. Sequence of the generation and transmission investment with a reactive TSO.

The generator can connect to the network with a probability $p$ (and so does not connect with a probability of 1-p). This uncertainty is not intrinsically quantifiable. However it is possible to attribute it a subjective value to evaluate the robustness of assumptions of a study for network investment.

If the generator connects, the system must successively support:

- $C W(d)$, the total congestion cost discounted for $d$ years, while the TSO is upgrading the network

- $C U(d, 10)$, the residual total congestion cost discounted for ten years ${ }^{14}$ after upgrading the network, that is to say $d$ years after the connection of the generator,

\footnotetext{
${ }^{14}$ See footnote 12 .
} 
- $I .(1+a)^{-d}$, the discounted cost of this upgrading $d$ years after the beginning of our study (corresponding to the moment when the generator is ready to generate power).

If the generator does not connect, the network investment cost and the congestion cost to the TSO are null. The table 2 summarises these two cases.

Table 2

Costs faced by the reactive TSO depending on the effective connection of the generator

\begin{tabular}{|c|c|c|c|}
\hline TSO & $\begin{array}{c}\text { invests } \\
\text { Probability } \\
p\end{array}$ & $\begin{array}{c}\text { does not } \\
\text { invest } \\
\text { Probability } \\
1-p\end{array}$ & Expected social cost \\
\hline $\begin{array}{l}\text { waits for the } \\
\text { connection } \\
\text { of the power } \\
\text { plant before } \\
\text { studying and } \\
\text { upgrading } \\
\text { the network }\end{array}$ & $\begin{array}{c}C W(d)+ \\
C U(d, 10)+ \\
I .(1+a)^{-d}\end{array}$ & $0+0$ & 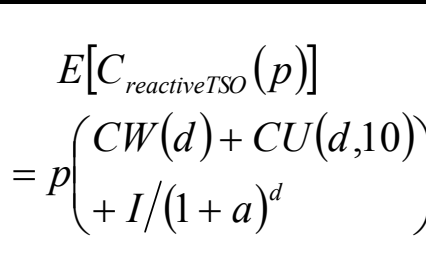 \\
\hline
\end{tabular}

Expected cost for a proactive TSO

A proactive TSO anticipates the connection of the generator. He studies the network upgrading and asks for the administrative agreements to build the powerline (without building it) before the power station be planned or approved. The network is upgraded only once the power plant is effectively approved and is ready to be connected. Figure 5 illustrates the sequence of the generation and transmission investments. The new transmission line and the new power plant begin to serve at the same time because the TSO has anticipated the network upgrading. 
Rious et al.: Power Transmission Network Investment

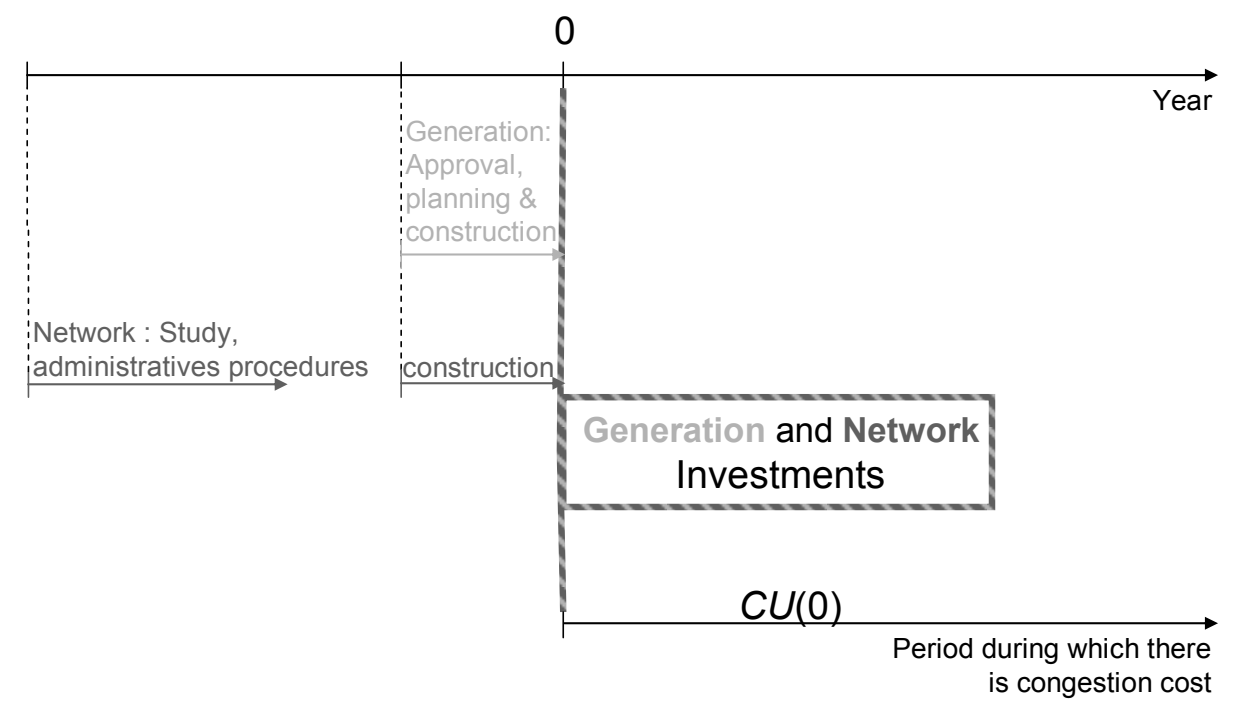

Figure 5. Sequence of the generation and transmission investment with a proactive TSO.

The generator can connect with a probability $p$ (and so does not connect with a probability $1-p$ ). If the generator connects to the network, the system must successively support:

- $\quad C U(0,10+d)$, the residual total congestion cost discounted for $10+\mathrm{d}$ years after the power plant connecting and the network upgrading so that we evaluate congestion costs over the same duration whatever the moment when the network is effectively upgraded,

- and $I$, the upgrading cost.

In case of the generator not connecting, the congestion cost is null and the cost of anticipation linked to the non realisation of the anticipated event is a share $\alpha$ of the total investment transmission cost. Indeed, the transmission investment is not done but the preliminary steps are however realized. The cost $\alpha . I$ includes not only the cost to anticipate to the TSO but also the cost born by the local authorities involved in the process of administrative agreements. Moreover, the cost $\alpha . I$ takes into account the a posteriori discounting of the cost to anticipate. We assume the cost to anticipate $\alpha . I$ is proportional to the investment cost because a power line faces all the more oppositions that it is longer and goes through a wider area. Table 3 summarises these costs. 
Table 3

The costs faced by a proactive TSO depending on the effective connection of the generator

\begin{tabular}{|c|c|c|c|}
\hline TSO Generator & $\begin{array}{c}\text { invests } \\
\text { Probability } p\end{array}$ & $\begin{array}{c}\text { does not } \\
\text { invest } \\
\text { Probability } \\
1-p\end{array}$ & Expected social cost \\
\hline \begin{tabular}{|l} 
Studies \\
beforehand the \\
installation of \\
the power \\
plant and \\
invests at the \\
same time as \\
the generator
\end{tabular} & $\begin{array}{c}I+ \\
C U(0,10+d)\end{array}$ & $\alpha . I+0$ & $\begin{array}{c}E\left[C_{\text {proactiveTSO }}(p)\right] \\
=p(I+C U(d, 10)) \\
\quad+(1-p) \cdot \alpha \cdot I\end{array}$ \\
\hline
\end{tabular}

General condition for a proactive TSO to be efficient

We are searching for the necessary and sufficient condition for the proactive TSO to be more efficient than the reactive one from the point of view of the minimization of the expected social cost. This condition links the cost $\alpha$ to anticipate, the probability $p$ to connect a power plant and the difference $d$ in time to build a power plant and a power line such that the equation 3 is respected.

$$
E\left[C_{\text {proactive TSO }}(p)\right] \leq E\left[C_{\text {reactive TSO }}(p)\right]
$$

The equation 4 equivalently expresses this relation.

$$
\alpha \leq p\left[\begin{array}{c}
(1+a)^{-d}+\alpha-1 \\
+\frac{C W(d)+C U(d, 10)-C U(0,10+d)}{I}
\end{array}\right]
$$

To interpret this formula, we consider the case of equality of the equation 4 and then define the limit of probability of "probability limit" $p_{\text {lim }}$ to connect a power plant.

\footnotetext{
${ }^{15}$ The term $C W(d)+C U(d, 10)-C U(0,10+d)$ can also be calculated as follows$$
C W(d)+C U(d, 10)-C U(0,10+d)=\sum_{y=1}^{d} \frac{C W_{y}-C U_{y}}{(1+a)^{y}}
$$ 


$$
p_{\lim }=\alpha /\left[\begin{array}{c}
(1+a)^{-d}+\alpha-1 \\
+\frac{C W(d)+C U(d, 10)-C U(0,10+d)}{I}
\end{array}\right]
$$

If the probability to connect a power plant is greater than $p_{\text {lim }}$, then the proactive TSO is more efficient than the reactive one ${ }^{16}$. The equivalence between the equations 3 and 4 then shows that the strategy of anticipation is all the more efficient that the probability $p_{\lim }$ is small. The interpretation of the equation 4 also consists in evaluating how the probability limit $p_{\text {lim }}$ varies with the cost $\alpha$ for anticipating and the difference $d$ in time to build a generation investment and a transmission one. For a given cost $\alpha$ for anticipating, $p_{\text {lim }}$ decreases when the difference $d$ between the time to build a power plant and a power line increases. This is because the congestion cost generally increases more quickly than the gain from postponing the network investment and its discounting. For a given difference $d, p_{\text {lim }}$ increases when the cost $\alpha$ to anticipate increases.

\section{A conservative evaluation of conditions for a proactive TSO to be efficient}

The study of partial derivatives of $p_{\text {lim }}$ versus and $d$ shows the following relationships between these variables and $p_{\text {lim }}$. $p_{\text {lim }}$ increases when $\alpha$ increases. And $p_{\text {lim }}$ decreases when $d$ increases under the assumption that the derivative of $C W(d)+C U(d, 10)-C U(0,10+d)$ is high enough (higher than the derivative of the term $(1+a)^{-d}$, which is very low). Table 2 shows some values of $p_{\text {lim }}$ for a set of values of $d$ and $\alpha$. We also make a conservative assumption on the level of the term $C W(d)+C U(d, 10)-C U(0,10+d)$. We assume that there is no congestion after investment (and therefore that $C U=0$ ) and $C W(d) / I$ follows a linear law with a value of $C W(d)$ close to the discounting for $d$ years of the annualized cost of investment over 20 years. This means that congestion exists and that it justifies the development of the network without inducing excessive congestion cost.

With the above assumptions, we show that the efficiency of the anticipation strategy is not obvious in all the possible situations. To be efficient, the strategy of anticipation of connections of new generators by the TSO requires appropriate conditions. Indeed, when the cost of anticipation is very high, $50 \%$ of the investment cost, and the difference of dynamics between generation and transmission investments is moderate (4 years), we notice that the anticipation of generation investments would be efficient only when their connection has an extremely high probability $(90 \%)$. However once the cost of anticipation

\footnotetext{
16 To the contrary, if the probability of connection $p$ is less than $p_{\text {lim }}$, then the reactive TSO is more efficient than the proactive TSO.
} 
decreases, anticipation becomes a more efficient strategy with lower probabilities of connection (until less than 50\%). When the difference in dynamics between generation and transmission investments increases, the anticipation strategy becomes more efficient in just over one in four cases with a cost of anticipation of $50 \%$ and in more than one in two with a moderate cost of anticipation of $15 \%$.

Table 4

Evaluation of the limit probability for some values of $d$ and $\alpha$

\begin{tabular}{|c|c|c|c|c|c|c|}
\hline $\begin{array}{l}\text { Difference in dynamics } d \text { in } \\
\text { years }\end{array}$ & \multicolumn{3}{|c|}{4} & \multicolumn{3}{|c|}{7} \\
\hline $\begin{array}{l}\text { Ratio congestion cost before } \\
\text { network investment over the } \\
\text { network investment cost } \\
C W(d) / I\end{array}$ & \multicolumn{3}{|c|}{0,3} & \multicolumn{3}{|c|}{0,6} \\
\hline Cost of anticipation $\alpha$ in $\%$ & 50 & 15 & 3 & 50 & 15 & 3 \\
\hline Limit probability $p_{\text {lim }}$ in $\%$ & 93 & 81 & 46 & 73 & 45 & 14 \\
\hline
\end{tabular}

These results must be moderated because it is assumed that the congestion cost before the network upgrade is just sufficient to justify that the network be upgraded. Considering the expression of $p_{\text {lim }}$, we understand that a higher value of the congestion cost, before $(C W)$ or after $(C U)$ the grid reinforcement leads to lower values for the limit probability than the ones previously calculated. Our results are thus rather conservative. Even if they clearly show that the efficiency of the anticipation of new connections and of the associated network reinforcement is uncertain, but asks to consider specific situations where administrative costs are low or moderate or when the potential of new connection is not negligible.

\section{Conclusion}

By favouring the construction of new power plants, the anticipation of transmission investment has a central role in coordinating the generation and transmission investments. Regarding this statement, the paper has brought two contributions.

First this paper has shown that the liberalization of the power system has complicated transmission planning while making its anticipation even more essential, for two reasons. First, the Combined Cycle Gas Turbines and the wind farms which stand for the biggest amount of generation investments in Europe and in the USA can be built in less time than the transmission lines that should transmit the power from these power stations through the core of the network. Second, the duration of the administrative procedures required before the 
construction of a powerline stands for almost three quarter of the time to realize a powerline.

The second contribution of this paper is the model. Our model allows evaluating the efficiency of the strategy of anticipating the connection of power plants to the network for the TSO in terms of the minimization of the network cost when anticipation is costly because of the administrative procedures. Our conclusions about the efficiency of anticipation are more balanced than those of other studies like Brattle Group (2007) or Sauma and Oren (2006). Indeed, despite conservative assumptions about the amplitude of the congestion created by the new generator, our model shows that it is efficient to anticipate the connection of a new generator when the difference of the investment dynamics between power generation and transmission is significant ( 7 years) and/or when the cost of anticipation is moderate.

In addition to the compensation of the difference in dynamics between transmission and generation investments, anticipating the connection of new generators to develop the network has other virtues. This approach by the TSO, if it is public, can stimulate the dialog with other stakeholders in the electricity system and identify in advance a shared view of the system evolution (Bråten, 2004). In particular, it allows to provide the market participants with new opportunities in terms of location and primary energy. It allows also to report any problems with security of supply. Some generation units may be geographically concentrated, while the transmission network cannot or will not be able to evacuate their whole production to consumption centres in a timely manner. Furthermore, the sooner the residents are involved in the transmission investment process, the easier the powerline would be built (Hughes, 2000; MacLaren Loring, 2007).

Our paper now opens the way to new questions: toward academic world, we pave the way to new works on this issue taking into account the limits of our study. Works need to be done to take into account the inclusion of market power (relying on the work by Sauma and Oren in 2006 and 2007), locational signals, incentive regulation for anticipation, the problem of investment incentive for generator without anticipation of grid development, or the effect of milestones payment of the connection tariffs to create increasing location commitment from generator. Toward the relationship between regulator and TSO, our work shows that efficient regulation should include anticipation as a core issue in the regulated TSO activities. Lastly, toward TSO directly, we think that even in the case of incomplete regulation on this issue, TSO should perform anticipation of network investments by their own means as it solves the operational problem of congestion management in advance. 


\section{References}

Brattle Group (2007) "A review of Tennet's connections policy." July, http://www.tennet.org/english/images/Final\%20Brattle\%20Report $\% 20$ on \%20TenneT\%20connections\%2008 0807 tcm43-14968.pdf.

Bråten J. (2004) "Estimating benefits. Uncertainty, scenario design and the analysis of benefits." European Transmission Investment Conference. Copenhagen, Denmark, $18-19^{\text {th }}$ October.

Brennan Timothy (2009) "Network effects in Infrastructure Regulation: Principles and paradoxes". Review of Network Economics, 8:279-301.

Christiner Gerhard (2007) "VERBUND-Austrian Power Grid. Austria Completing the $380 \mathrm{kV}$-Ring. Authorization Procedures and Major Problems." CEER Electricity Infrastructure Workshop. $13^{\text {th }}$ February, Brussels.

DGEMP (2003) Coûts de référence de la production électrique. Ministère de l'Économie, des Finances et de l'Industrie. Paris, December.

ETSO (2006) "Overview of the administrative procedures for constructing 110 $\mathrm{kV}$ to $400 \mathrm{kV}$ overhead lines." $5^{\text {th }}$ December, www.etso-net.org.

ETSO (2007) "European Wind Integration Study (EWIS). Towards a Successful Integration of Wind Power into European Electricity Grid. Final Reports." $15^{\text {th }}$ January, www.etso-net.org.

EWEA (2005) "Support Schemes for Renewable Energy. A Comparative Analysis of Payment Mechanisms in the EU", http://www.ewea.org/fileadmin/ewea_documents/documents/projects/rexp ansion/050620 ewea report.pdf.

FERC (2007) "Order Granting Petitionfor Declaratory Order." $19^{\text {th }}$ April, http://www.ferc.gov/whats-new/comm-meet/2007/041907/E-5.pdf.

Finon Dominique, Perez Yannick (2007) "The social efficiency of instruments of promotion of renewable energies: A transaction-cost perspective." Ecological Economics, 62: 77-92.

Glachant Jean-Michel (2006) "Generation technology mix in competitive electricity markets" in Investments frame and incentives in the electrical industry, Lévêque F. (ed). Kluwer.

Hogan William (1992) "Contrat Networks for Electric Power Transmission," Journal of Regulatory Economics, 4: 211-42.

Hughes R. (2000) "Environmental Impact Assessment and Stakeholder Involvement." International Institute for Environment and Development. Available on www.iied.org/pubs/pdf/full/7789IIED.pdf.

Joskow Paul. (2006) "Patterns of transmission investment", in Lévêque François. (ed), Competitive Electricity Markets and Sustainability, Edward Elgar, 131-186. 
Joskow Paul. (2008) "Incentive Regulation and Its Application ot Electricity Networks." Review of Network Economics, 7: 547-60.

MacLaren Loring Joyce (2007) "Wind energy planning in England, Wales and Denmark: factors influencing project success." Energy Policy, 35: 26482660.

REALISEGRID (2010) "Possible criteria to assess technical-economic and strategic benefits of specific transmission projects." $29^{\text {th }}$ April. Available at

http://realisegrid.rseweb.it/content/files/File/Publications\%20and\%20results/Deliverable_REA LISEGRID 3.3.1.pdf

Nordel (2004) "Priority Cross-sections. Joint Nordic Analyses of Important Cross-sections in the Nordel System." $11^{\text {th }}$ June, www.nordel.org.

Rious Vincent, Dessante Phillipe, Perez Yannick (2009) "Is combination of nodal pricing and average participation tariff the best solution to coordinate the location of power plants with lumpy transmission investments?" Working Papers RSCAS 2009/14, ROBERT SCHUMAN CENTRE FOR ADVANCED STUDIES, Loyola de Palacio Programme on Energy Policy.

Rious Vincent, Glachant Jean-Michel, Perez Yannick, Dessante Phillipe. (2009) "L'insuffisance des signaux de localisation pour la coordination entre la production et le transport d'électricité dans les systèmes électriques libéralisés", Revue Economique Volume, 60: 819-29.

Roques Fabien, Newbery David, Nuttall William (2008) "Fuel mix diversification incentives in liberalised electricity markets: a mean-variance portfolio theory approach." Energy Economics, 30:1831-49.

Royal Academy of Engineering (RAE) (2004) The cost of generating electricity, London, March.

Sauma Enzo, Oren Shmuel. (2006) "Proactive planning and valuation of transmission investments in restructured electricity markets." Journal of Regulatory Economics, 30: 261-90.

Sauma Enzo, Oren Shmuel. (2007) "Economic criteria for planning transmission investment in restructured electricity markets." IEEE Transactions on Power Systems, 22: 1394-1405.

Statnett (2005) “Grid Development Plan 2005-2020.” June, www.statnett.no.

Stoft Steven (2006) "Problems of transmission investment in a deregulated power market", in Lévêque F. (ed), Competitive Electricity Markets and Sustainability, Edward Elgar, 87-130.

UCTE (2008) "UCTE Transmission Development Plan", www.ucte.org

U.S. Department of Energy (USDoE) (2006) "National Electric Transmission Congestion Study." August, www.nietc.anl.gov/documents/docs/Congestion_Study_2006-9MB.pdf. 